\title{
EFFECT OF NARINGENIN ON OXIDATIVE STRESS IN THE HEART TISSUE OF TYPE 1 DIABETIC WISTAR RATS
}

\author{
PIOTR BRAMORA ${ }^{1 *}$, WERONIKA BORYMSKA ${ }^{1}$, MARIA ZYCH ${ }^{1}$, \\ and ILONA KACZMARCZYK-SEDLAK ${ }^{1}$
}

${ }^{1}$ Department of Pharmacognosy and Phytochemistry, Faculty of Pharmaceutical Sciences in Sosnowiec, Medical University of Silesia in Katowice, Jagiellońska 4, 41-200 Sosnowiec, Poland

\begin{abstract}
Cardiovascular complications are the main cause of death in people with type 1 and type 2 diabetes. Oxidative stress is believed to be the main mechanism that triggers many pathological changes, which may eventually lead to diabetic cardiomyopathy. Flavonoids are present in many plant species and have various biological activities. The aim of this study was to investigate the effect of naringenin on selected parameters of oxidative stress in the heart tissue of rats with type 1 diabetes. Diabetes was induced by intraperitoneal injection of streptozotocin. Naringenin in doses of 50 and $100 \mathrm{mg} / \mathrm{kg}$ body weight was administered orally for 28 days. Then, rats were euthanized to obtain hearts for laboratory tests. In tissue homogenates, antioxidant enzymes and markers related to oxidative-antioxidant imbalance, such as reduced and oxidized glutathione, advanced oxidation protein products, malondialdehyde, vitamin $\mathrm{C}$ and oxidative stress index were determined. This flavonoid counteracted the development of adverse changes in the organism caused by type 1 diabetes. It was noted that the oxidative damage of proteins and lipids was alleviated, as well as a reduction in the value of the oxidative stress index in the heart. These results indicate the possible utility of naringenin in antidiabetic therapy.
\end{abstract}

Keywords: type 1 diabetes, oxidative stress, heart tissue, naringenin, Wistar rats

Diabetes mellitus (diabetes mellitus) is a heterogeneous disease characterized by elevated levels of glucose in the blood. Based on the latest data, it is expected that the number of patients will exceed 640 million by 2040 . Therefore, it will be a serious burden for future healthcare. There are many types of diabetes with different causes. Type 1 and 2 are most often described in world literature and are also most common in the human population. The essence of the disease is the impairment or loss of the ability to produce and secrete insulin by the beta cells of the Langerhans islets (1-3).

Type 1 diabetes is diagnosed in children and adults. The typical clinical symptoms in the youngest patients are polyuria, polydipsia, and diabetic ketoacidosis. However, in adults, the above-mentioned pathological phenomena do not have to be present, which makes it difficult to make an accurate diagnosis in the initial stage of the disease. Risk factors include genetic predisposition along with autoimmune diseases, frequent childhood infections, and pre-eclampsia in pregnancy.

Dangerous for diabetic patients are the widely understood complications, which are microangiopathies (retinopathy, nephropathy, neuropathy) and macroangiopathies (arteriosclerosis, including cerebral and coronary arteries). The main cause of the mentioned changes in the cytoarchitectonics of tissues is long-term hyperglycemia, which leads to the excessive generation of free radicals. This causes an imbalance of pro-oxidant-antioxidant balance, referred to in the literature as oxidative stress $(1,4)$.

Numerous publications suggest that oxidative stress also occurs in the heart causing damage to proteins, lipids, DNA fragmentation, disruption of the autophagy process, and impaired production of nitric oxide. There is also inflammation manifested by a release of cytokines and chemokines by damaged cells and leukocytes infiltrating the tissue. Histopathological and immunohistochemical examinations showed tissue remodeling consisting of cardiomyocyte hypertrophy, interstitial fibrosis, and apoptosis. In addition to hyperglycemia, it is believed that high levels of free fatty acids and hypoinsulinemia are the main factors causing the pathological phenomena described above. Oxidative stress and other mentioned pathomechanism may eventually

* Corresponding author: e-mail: d200746@365.sum.edu.pl 
lead to diabetic cardiomyopathy (5-9) and exogenous insulin treatment may not be enough to stop the progress of such changes $(6,10,11)$.

Therefore, it is necessary to intensify work on the search for therapies supporting insulin therapy based on compounds of natural origin, which will reduce the likelihood of hypoglycemia episodes and adverse drug reactions (11).

Naringenin is a chemical compound classified as a flavonoid. It is mainly found in citrus fruits, especially in bitter oranges (Citrus aurantium), grapefruits (Citrus paradisi), lemons (Citrus limon), and bergamot (Citrus bergamium). According to available literature, it can be concluded, that the above compound has antidepressant and anti-inflammatory properties and prevents diabetic neuropathy. It also protects against oxidative stress, inhibits the process of apoptosis by protecting mitochondria, and acts as a hypoglycaemic and lipid-lowering drug in type 1 diabetes. Additionally, it has a broadly defined antitoxic effect. Naringenin protected laboratory rats from the toxic influence of doxorubicin, isoproterenol, rotenone, 6-hydroxydopamine, lipopolysaccharide, 1-methyl-4-phenyl-1,2,3,6-tetrahydropyridine, daunorubicin, gentamicin, cisplatin, cadmium, benzo(a)pyrene, N-Nitroso-diethylamine, and 1,2-dimethylhydrazine (12).

Despite intensive scientific research on the above compound of plant origin, the direct protective effect on the heart muscle in the course of type 1 diabetes has not been definitely documented (13). So far, an experiment was carried out in a diabetic model with myocardial infarction, but it was not the same model as used in this study (14). In this study, an attempt was made to determine the influence of naringenin on the development of oxidative stress in the heart tissue using rats with streptozotocin-induced diabetes. Therefore, evaluation of the level of oxidative stress markers, determination of the efficiency of the antioxidant system was made. In addition, the tissue oxidative stress index was estimated by examining the total oxidative state along with the complete antioxidant response.

\section{MATERIALS AND METHODS}

\section{Laboratory animals}

Three-month-old male Wistar rats were obtained for the experiment from the Centre of Experimental Medicine at the Medical University of Silesia in Katowice and were acclimatized for one week. The animals were kept in an appropriately prepared room with a constant temperature $\left(21 \pm 2^{\circ} \mathrm{C}\right)$, with constant air humidity $(50-70 \%)$, where a standard 24-hour cycle was provided $(12 \mathrm{~h}$ light phase $/ 12 \mathrm{~h}$ dark phase). Rats received complete food (Labofeed B, Wytwórnia Pasz "Morawski", Kcynia, Poland) and unlimited water. Approval No. 36/2015 of the Local Ethical Committee operating at the Medical University of Silesia in Katowice was obtained for all procedures performed in the study. Rats were sacrificed by general anesthesia using ketamine and xylazine mixture.

\section{Induction of type 1 diabetes}

In this study, the type 1 diabetes model was used, which is well described in the available literature (15-17). Streptozotocin (STZ) at a dose of $60 \mathrm{mg} / \mathrm{kg}$ body weight by intraperitoneal (i.p.) injection was used to induce the disease. A solution of STZ was obtained by dissolving it in $0.1 \mathrm{M}$ citrate buffer at a $\mathrm{pH}$ of 4.5. The control group received citrate buffer alone. The next step was to measure blood glucose levels in whole capillary blood 14 days after STZ administration, with the MicroDot glucometer. The tip of the tail was punctured for this purpose. Rats with blood glucose levels above $200 \mathrm{mg} / \mathrm{dL}$ were qualified for the next stage of the experiment.

\section{Experiment design}

All rats were divided into four groups:

1. Group C: non-diabetic, control rats given water $(n=9)$,

2. Group DM: rats with streptozotocin-induced diabetes mellitus receiving water $(\mathrm{n}=8)$,

3. Group DM+N50: diabetic rats receiving naringenin (Sigma-Aldrich, St. Louis, MO, USA) at a dose of $50 \mathrm{mg} / \mathrm{kg}$ body weight per os $(\mathrm{n}=8)$,

4. Group DM+N100: diabetic rats receiving naringenin (Sigma-Aldrich, St. Louis, MO, USA) at a dose of $100 \mathrm{mg} / \mathrm{kg}$ body weight per os $(\mathrm{n}=8)$.

The rats were weighed weekly. The amount of feed and water was monitored once a day. The test compound was administered once daily. Naringenin suspended in water was administered at volume of $1 \mathrm{ml} / \mathrm{kg}$ body weight. Two control groups ( $\mathrm{C}$ and $\mathrm{DM}$ ) were vehicle-treated with water at a volume of $1 \mathrm{ml} / \mathrm{kg}$ body weight.

The experiment lasted 28 days. Then the rats were anesthetized by i.p. injection with a mixture of ketamine (Ketamina 10\%, Biowet Puławy Sp. z o. o., Puławy, Poland) and xylazine (Xylapan, Vetoquinol Biowet, Gorzów Wlkp., Poland) at the concentration 
of $87.5 \mathrm{mg} / \mathrm{kg}$ body weight and $12.5 \mathrm{mg} / \mathrm{kg}$ body weight.

Biochemical determinations were performed in the heart homogenates.

\section{Obtaining heart homogenates for biochemical analysis}

The heart was homogenized in PBS $(10 \mathrm{mmol} / \mathrm{L})$ in order to obtain $10 \%(\mathrm{v} / \mathrm{w})$ homogenates. The obtained homogenate was then centrifuged $(10000 \times \mathrm{g}$, $\left.4^{\circ} \mathrm{C}, 15 \mathrm{~min}\right)$. The resulting supernatant was frozen to be used for biochemical determinations.

\section{Measurement of protein content in the heart}

The method developed by Lowry (18) was applied. In this procedure, copper-protein complexes were formed. The copper ions were reduced with the Folin-Ciocalteu reagent, producing an intense blue color. Then the absorbance was read at the analytical wavelength of $750 \mathrm{~nm}$.

\section{Measurement of antioxidant enzymes activity}

The enzymatic activity of superoxide dismutase (SOD) EC 1.15.1.1, catalase (CAT) EC 1.11.1.6, and glutathione peroxidase (GPx) EC 1.11.1.9 was achieved with the use of commercial kits from Cayman (Cayman Chemicals, Ann Arbor, MI, USA; kit reagent: SOD No. 706002, CAT No. 707002, GPx No. 703102).

\section{Assessment of the level of markers of oxidative stress}

The concentration of reduced (GSH), oxidized (GSSG), and total (tGSH) glutathione were determined using a reagent kit (GSH/GSSG No. 703002) manufactured by Cayman (Cayman Chemicals, Ann Arbor, MI, USA). Vitamin C concentration was estimated using the method developed by Jagota and Dani. First, trichloroacetic acid was added in order to lower the $\mathrm{pH}$ of the reaction. This is followed by the reduction of the Folin-Ciocalteu reagent by ascorbic acid. The amount of the reaction product formed is determined spectrophotometrically at a wavelength of $750 \mathrm{~nm}$ (19). Advanced protein oxidation products (AOPP) were determined according to the procedure described by Witko-Sarsat (20). It consists of the formation of a colored oxidation product of potassium iodide in the presence of glacial acetic acid. In order to measure the AOPP concentration, a calibration curve is made of chloramine $\mathrm{T}$ and the spectrophotometric measurement of the yellow solution is made at $340 \mathrm{~nm}$. In contrast, malondialdehyde (MDA) was determined according to Buege and Aust (21), using its reaction with thiobarbituric acid (TBA). A complex with a pink tint is formed. The concentration of MDA (proportional to color intensity) was measured at a wavelength of $532 \mathrm{~nm}$.

\section{Estimation of the oxidative stress index by examining the total oxidative status along with the total antioxidant response}

Total oxidative status (TOS) and complete antioxidant response (TAR) were determined according to the methods proposed by Erel et al. $(22,23)$. The essence of the method in which TOS is measured is the oxidation of $\mathrm{Fe}^{2+}$ to $\mathrm{Fe}^{3+}$ by oxidants in an acidic environment. Ion $\mathrm{Fe}^{3+}$ together with xylenol orange forms a complex compound, the content of which can be determined at a wavelength of $560 \mathrm{~nm}$. This reflects the amount of molecules that are oxidizing in a given biological material. In turn, TAR was investigated thanks to the Fenton o-dianisidine reaction. Hydroxyl radicals are generated which oxidize o-dianisidine to dianisidyl radicals. The yellow-brown color is the more intense the more oxidation processes increase. At the time of the correct response of the defense mechanisms to the increased amount of free radicals, a decrease in the color intensity of the analyzed samples is noted. The above phenomena can be measured spectrophotometrically at the analytical wavelength of $444 \mathrm{~nm}$. The values obtained on the basis of the above protocols were used to calculate the oxidative stress index (OSI=TAR/TOS).

A Tecan Infinite M200 Pro microplate reader with Magellan 7.2 software was used to read all the absorbances obtained.

\section{Statistical analysis of the results}

The obtained data were presented as the mean value \pm standard error of the mean (SEM). The normality of the results was then assessed using the Shapiro-Wilk test. Statistical analysis was performed by Student's t-test for unpaired (independent) observations, using the Statistica 13.3 software (TIBCO Software Inc.). The results for which $p<0.05$ were considered statistically significant.

\section{RESULTS}

\section{Weight of hearts and cardiac index}

The heart weight of rats from the DM, $\mathrm{DM}+\mathrm{N} 50$ and DM+N100 groups was significantly lower compared to the animals in group C. It should be emphasized that no significant changes in the weight of this organ were observed in the $\mathrm{DM}+\mathrm{N} 50$ and $\mathrm{DM}+\mathrm{N} 100$ rats in relation to the DM 
Table 1. Effect of naringenin on the heart weight and cardiac index of the rats.

\begin{tabular}{|c|c|c|c|c|}
\hline Type of parameter & $\mathrm{C}$ & $\mathrm{DM}$ & $\mathrm{DM}+\mathrm{N} 50$ & $\mathrm{DM}+\mathrm{N} 100$ \\
\hline Heart weight $(\mathrm{g})$ & $0.92 \pm 0.03$ & $0.65 \pm 0.03^{* * *}$ & $0.69 \pm 0.03^{* * *}$ & $0.66 \pm 0.03^{* * *}$ \\
\hline Cardiac index $(\mathrm{mg} / \mathrm{kg})^{\mathrm{a}}$ & $2.64 \pm 0.08$ & $2.92 \pm 0.07^{*}$ & $2.96 \pm 0.13^{*}$ & $2.72 \pm 0.15$ \\
\hline
\end{tabular}

${ }^{a}$ Cardiac index $=$ heart weight $(\mathrm{mg}) /$ total body weight $(\mathrm{kg})$. Results are presented as arithmetical means \pm standard error of the mean (SEM). ${ }^{*} \mathrm{p}<0.05,{ }^{* * *} \mathrm{p}<0.001$ vs. C group.

Table 2. Effect of naringenin on the activity of antioxidative enzymes, protein level, and vitamin C level in the heart of type 1 diabetic rats.

\begin{tabular}{|c|c|c|c|c|}
\hline Type of parameter & $\mathrm{C}$ & $\mathrm{DM}$ & $\mathrm{DM}+\mathrm{N} 50$ & $\mathrm{DM}+\mathrm{N} 100$ \\
\hline $\begin{array}{c}\text { SOD } \\
(\mathrm{U} / \mathrm{mg} \text { of } \mathrm{protein})\end{array}$ & $3.99 \pm 0.49$ & $4.90 \pm 0.36$ & $4.15 \pm 0.70$ & $4.47 \pm 0.41$ \\
\hline $\begin{array}{c}\mathrm{CAT}(\mathrm{nmol} / \mathrm{min} / \mathrm{mg} \text { of } \\
\mathrm{protein})\end{array}$ & $8.71 \pm 1.20$ & $25.75 \pm 5.71^{* *}$ & $30.82 \pm 4.60^{* * *}$ & $27.18 \pm 6.01^{* *}$ \\
\hline \begin{tabular}{c}
$\mathrm{GP}(\mathrm{x}) \begin{array}{c}\text { (nmol/min/mg of } \\
\mathrm{protein})\end{array}$ \\
\hline $\begin{array}{c}\text { Vitamin C } \\
(\mu \mathrm{g} / \mathrm{g} \text { of the heart) }\end{array}$
\end{tabular} & $127.55 \pm 6.44$ & $161.25 \pm 9.13^{* *}$ & $182.11 \pm 19.56^{*}$ & $170.27 \pm 10.01^{* *}$ \\
\hline $\begin{array}{c}\text { Protein } \\
(\mathrm{mg} / \mathrm{g} \text { of the heart) }\end{array}$ & $45.35 \pm 2.10$ & $47.23 \pm 2.12$ & $2.016 \pm 0.138$ & $1.996 \pm 0.094$ \\
\hline
\end{tabular}

Results are presented as arithmetical means \pm standard error of the mean (SEM). ${ }^{*} \mathrm{p}<0.05, * * \mathrm{p}<0.01$, $* * * \mathrm{p}<0.001$ vs. C group.

group (Table 1). In the case of the cardiac index (i.e. heart weight to body weight ratio), a significant increase in this parameter was noted in DM animals, as well as DM+N50 compared to $\mathrm{C}$ rats. However, naringenin administration at a dose of 50 and $100 \mathrm{mg} / \mathrm{kg}$ to the diabetic rats did not reduce the value of this index in relation to rats from the DM group. No differences were noted between $\mathrm{DM}+\mathrm{N} 50$ and $\mathrm{DM}+\mathrm{N} 100$ groups (Table 1).

\section{Activity of antioxidant enzymes in the heart}

SOD enzymatic activity in the heart did not differ significantly in all analyzed groups (Table 2). STZ injection resulted in an increase in the cardiac activity of both CAT and GPx compared to the $\mathrm{C}$ rats. Administration of naringenin in both doses did not affect CAT and GPx activity in the heart in relation to the DM rats. There were no statistical differences between used doses (Table 2).

\section{Level of glutathione in the heart}

The concentration of tGSH and GSH in the hearts of the DM rats did not differ in relation to the $\mathrm{C}$ rats. There were no significant differences between the groups of rats treated with both doses of naringenin and the DM group for both discussed parameters. Only the administration of the test compound at a dose of $100 \mathrm{mg} / \mathrm{kg}$ resulted in an increase in tGSH and GSH levels in the heart when compared to group C. It should be noted that in the case of GSSG and the GSH/GSSG ratio, no significant changes in concentrations between all groups were documented. There were no significant differences between the $\mathrm{DM}+\mathrm{N} 50$ and $\mathrm{DM}+\mathrm{N} 100$ rats with regard to these parameters (Figure 1).

\section{Concentration of oxidative damage markers in the heart}

The concentration of AOPP was significantly higher in the heart of the DM rats than in the $\mathrm{C}$ animals. Only naringenin at a dose of $50 \mathrm{mg} / \mathrm{kg}$ caused a decrease in the AOPP level in relation to the DM rats. Additionally, there was a significant increase in MDA concentration in the heart of the tested animals with diabetes. It should be emphasized that naringenin in both doses normalized this parameter in comparison with the DM rats. There were no statistical differences between the used doses with regard to both the AOPP and MDA parameters (Figure 2).

\section{Total oxidant/antioxidant status in the heart}

In the case of changes in TOS in the heart, only an increase in the value of this parameter was observed in the DM rats in relation to group $\mathrm{C}$ at the limit of statistical significance $(p=0.057)$. There were no significant differences in the values of TOS 

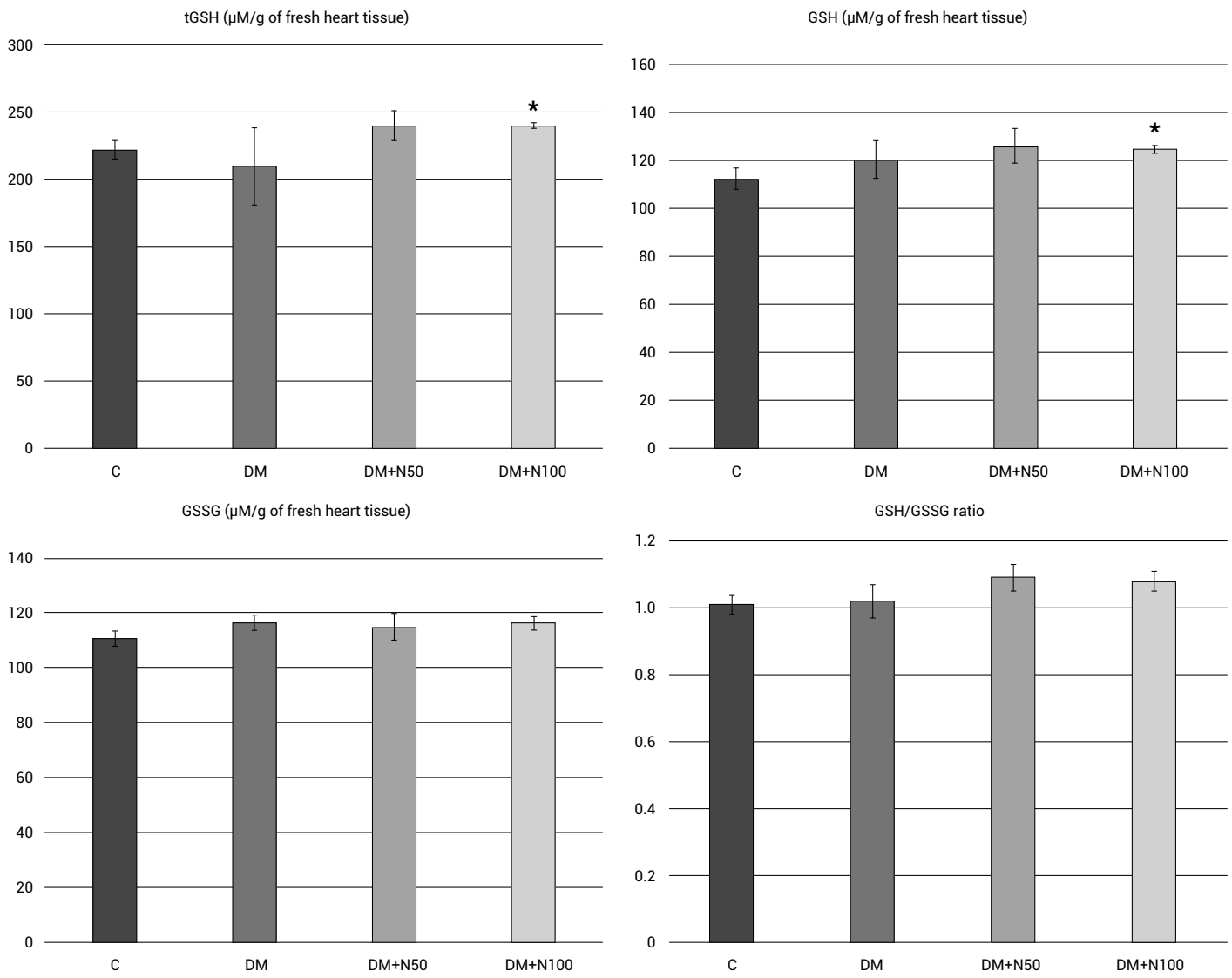

Figure 1. Effect of naringenin on the total, reduced, and oxidized glutathione concentration and GSH/GSSG ratio in the heart tissue of the type 1 diabetic rats. Data are expressed as the arithmetical mean \pm standard error of the mean (SEM). $* \mathrm{p}<0.05$ compared with the $\mathrm{C}$ group.

in the heart tissue between the groups of rats receiving the test compounds of natural origin and the DM rats. Additionally, the TAR in cardiac tissue was determined. On the basis of the obtained results, no significant decrease in the TAR value was observed in the hearts of the DM rats compared to the

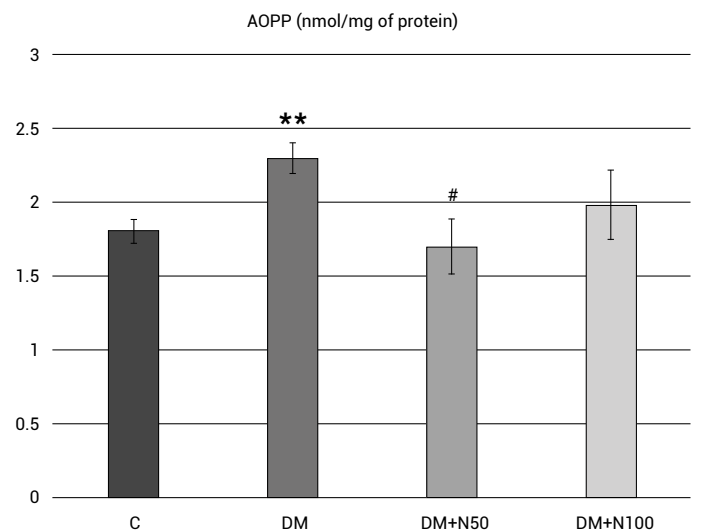

C group. On the other hand, the lower dose of naringenin, $50 \mathrm{mg} / \mathrm{kg}$, showed a tendency $(\mathrm{p}=0.099)$ to increase the TAR level in relation to the DM group. Based on TOS and TAR, OSI was estimated. In the group of DM rats, the values of this parameter in the heart were higher than in the $\mathrm{C}$ animals and showed

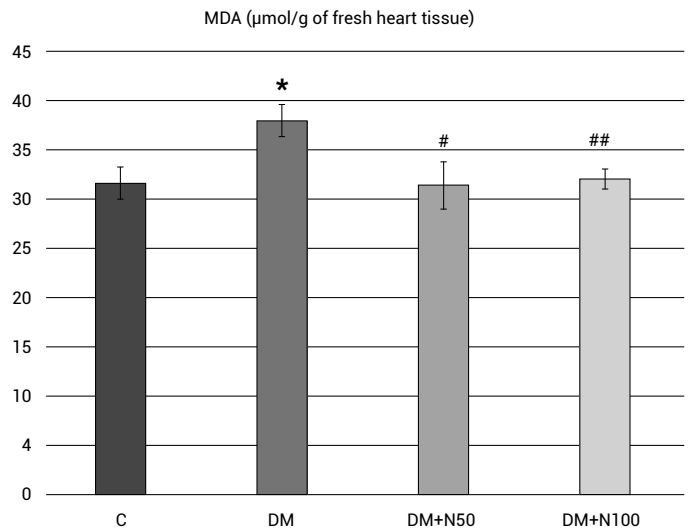

Figure 2. Effect of naringenin on the oxidative damage markers concentration in the heart tissue of the type 1 diabetic rats. Data are expressed as the arithmetical mean \pm standard error of the mean (SEM). ${ }^{*} \mathrm{p}<0.05$ compared with the $\mathrm{C}$ group; $\# \mathrm{p}<0.05$ compared with the DM group, \#\#p $<0.01$ compared with the DM group. 

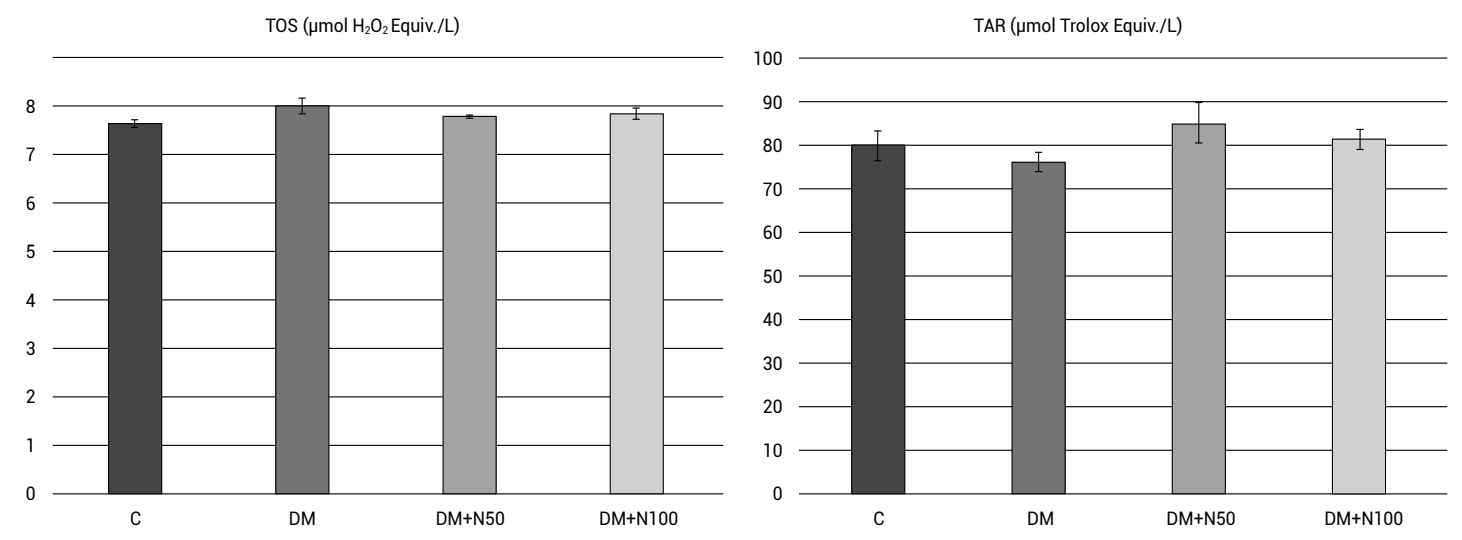

Figure 3. Effect of naringenin on the total oxidative status, total antioxidant response, and oxidative stress index in the heart tissue of the type 1 diabetic rats.

Data are expressed as the arithmetical mean \pm standard error of the mean (SEM).

$* \mathrm{p}<0.05$ compared with the $\mathrm{C}$ group;

$\# \mathrm{p}<0.05$ compared with the DM group.

statistical significance. Different results were recorded for the DM+N100 group, where there was a decrease in the OSI value in relation to the DM group. Moreover, the observed change was significant after statistical analysis of the obtained results. There were no significant differences between DM+N50 and $\mathrm{DM}+\mathrm{N} 100$ rats with regard to all these parameters (Figure 3).

\section{Level of vitamin $C$ in the heart}

In this experiment, the concentration of endogenous low-molecular antioxidant vitamin $\mathrm{C}$ was also determined. The obtained changes in the concentration of this antioxidant, such as a decrease in its concentration in the heart of the DM group compared to the $\mathrm{C}$ group and an increase in rats treated with two doses of naringenin compared to DM were not significant. No differences were noted between $\mathrm{DM}+\mathrm{N} 50$ and $\mathrm{DM}+\mathrm{N} 100$ groups (Table 2).

\section{Concentration of protein in the heart}

In the case of soluble protein concentration in cardiac tissue homogenates, no significant differences were found between all groups included in the experiment (Table 2).

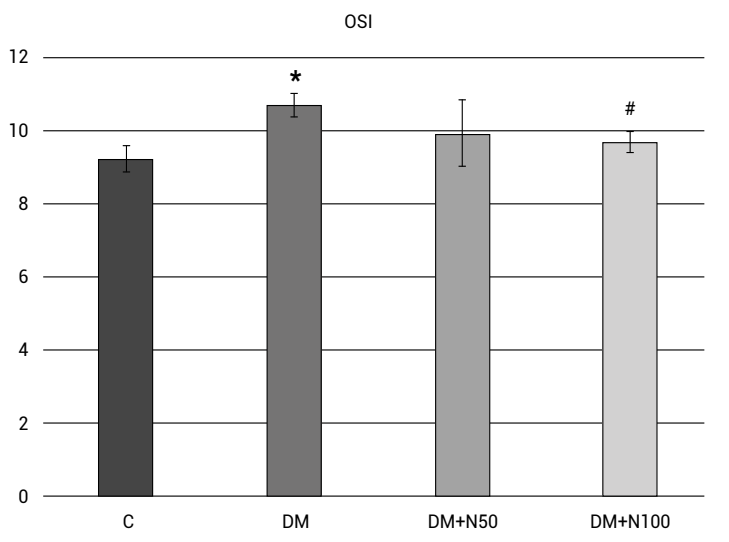

\section{DISCUSSION}

In recent years, the percentage of experiments with potential antioxidants such as vitamins and nonvitamin compounds has increased. Aimed at demonstrating their role in preventing pathological changes, including micro- and macroangiopathies developed as a result of experimental diabetes mellitus in laboratory animals (24-30).

In this study, an attempt was made to assess the influence of naringenin on the development of pathological changes related to oxidative stress in the heart in the course of type 1 diabetes. For this purpose, the streptozotocin diabetes model was used (15-17).

There was a significant decrease in heart weight in diabetic rats, combined with an increase in the cardiac index which is consistent with the literature $(31,32)$. The observed increase in the ratio of heart weight to body weight indicates organic changes in the heart. The probable hypertrophy is caused by the accumulation of cholesterol, triglycerides, phospholipids, and protein glycated in the muscle (31). Indirect evidence of the above phenomenon is a disturbed lipid profile, in which there was 
an increase in total cholesterol, triglycerides, lowdensity lipoproteins with a simultaneous decrease in high-density lipoproteins in these DM rats which was shown in the previous publication. Additionally, there was a significant decrease in body weight (33), which caused an increase in the heart mass to body mass ratio. Both doses of naringenin did not contribute to an increase in heart weight, nor to a decrease in the cardiac index in DM rats.

The concentration of soluble protein in heart homogenates in diabetic rats receiving compounds of natural origin orally was similar to the values obtained in healthy and diabetic rats.

In contrast, $\mathrm{Hu}$ et al. (34) found that streptozotocin diabetes excessively activates proteolytic pathways in the heart muscle of rats. The initiator of these processes is the state of insulinopenia. Actin decomposition by activation of the ubiquitinproteasome system has been observed, which may explain the development of systolic heart failure in diabetic patients.

The lack of observed changes in parameters in the treated group of animals may result from the too short duration of the experiment.

A single administration of streptozotocin increased the activity of CAT, GPx and but did not change the activity of SOD in relation to the $\mathrm{C}$ group. On the basis of the available literature, it can be concluded that the activity of the above-mentioned antioxidant enzymes may increase (35-37) or decrease (38-45) in tissue homogenates obtained from diabetic rats. Probably different types of cells building organs that perform different functions in the body react differently to oxidative stress caused by high glucose levels $(46,14)$. No changes in CAT, GPx, and SOD activity in relation to the DM rats were found in animals receiving the test compound. On the basis of the previous studies on the effect of citrus flavonoids, it is concluded that compounds increase the activity of SOD, CAT, and GPx in the cardiac tissue of rats with streptozotocin diabetes (36, 39, 47-49). Hai Li et al. (14) tried to determine the effect of naringenin on oxidative stress and organic changes in heart tissue in type 1 diabetic rats with induced myocardial infarction. For this purpose, the animals received naringenin at a dose of 25 and $50 \mathrm{mg} / \mathrm{kg}$ body weight for a period of 4 weeks after STZ exposure. There was no increase in the activity of SOD, GPx in the myocardium, and no reduction in glycemia compared to control. Similar observations were made by You et al. (50), investigating the influence of naringenin on oxidative stress in $\mathrm{H} 9 \mathrm{c} 2$ cardiomyocytes exposed to high glucose concentration in the culture medium. On the other hand, a team of researchers led by Kapoor (51) tried to demonstrate the hepatoprotective role of naringenin in the course of diabetes. They observed an increase in the level of SOD, CAT, and GPx activity in the liver after the administration of said compound at a dose of $50 \mathrm{mg} / \mathrm{kg}$ for 30 days in diabetic rats. The noted differences in enzymatic activity are related to the fact that the response to the disturbance of the pro-oxidant-antioxidant balance is different. It depends on the amount of produced free radicals in the tissue/organ, the type of tissue, and the duration of exposure $(52,53)$.

Glutathione is an important intracellular free radical scavenger and a substrate for many important enzymes. It plays a significant role in the degradation of hydrogen peroxide by oxidizing from the reduced GSH to the oxidized GSSG $(54,55)$. The ratio of GSH to GSSG often reflects the cellular redox balance. In diabetes mellitus, the level of GSH in the serum and organs is generally low $(4,56,57)$. There were no differences in the concentration of tGSH, GSH, GSSG, and changes in the GSH/GSSG ratio in the hearts of rats with type 1 diabetes compared to the $\mathrm{C}$ rats. It should be mentioned that per os naringenin administration did not change the concentration of $\mathrm{tGSH}, \mathrm{GSH}, \mathrm{GSSG}$, and the GSH/GSSG ratio in relation to the DM of rats. Taking into account the fact that the concentration of GSH, GSSG, and the level of GSH/GSSG ratio are indicators of the tissue's antioxidant capacity to defend itself against free radicals, it can be concluded that rat hearts are not easily susceptible to oxidative stress during the time after STZ administration.

Shrilatha et al. (58) found that in mice with type 1 diabetes, the level of free radicals in the testes and epididymal sperm gradually increases over time after STZ injection. It can be hypothesized that a similar phenomenon occurred in the hearts of rats in this experiment. Initially, there is an adaptive GSH-dependent antioxidant response in cardiomyocytes. This is evidenced by the increased pool of GSH in cardiomyocytes (59). A decrease in GSH concentration with a simultaneous increase in GSSG would probably take place in the longer term. Then the picture of chronic diabetes would develop, combined with a decrease in the compensation possibilities on the part of the organism (60). No change in the above parameters should be accurately determined in further scientific experiments with different doses and longer duration.

An increase in the concentration of MDA in the heart of rats with streptozotocin diabetes mellitus compared to healthy rats was documented. The results are in line with data available in the 
world literature on diabetes research $(47,49,61$, 62). After administering naringenin to diabetic animals, a lower MDA concentration in tested samples was demonstrated as compared to diabetic control rats. The obtained results are consistent with the observations made by Hai Li (14). In this experiment, the cardioprotective effect of naringenin was demonstrated in rats with type 1 diabetes with induced myocardial infarction. The rats were administered the naringenin at a dose of 25 and $50 \mathrm{mg} / \mathrm{kg}$ for 30 days, which lowered the MDA in the hearts after infarction. Mention should be made, that naringenin administered at a dose of $50 \mathrm{mg} / \mathrm{kg}$ to the diabetic rats for 30 days also resulted in a reduced concentration of MDA in another organ - the liver (51). Another citrus flavonoid, nobiletin, administered to the diabetic rats also reduced MDA level in the cardiac tissue, which was elevated after STZ injection (48). There are also other compounds such as flavonoids luteolin or phenolic compounds called mangiferin, which revealed similar beneficial effect in cardiac tissue of diabetic rats as far as MDA level is concerned $(37,63)$. The observed protective effect of naringenin may be due to its lipophilic properties. This flavonoid easily penetrates the lipid bilayer of the cell membrane and forms unstable bonds with the hydrophilic part of phospholipids. This leads to an increase in the strength of the cell membrane, which prevents lipid peroxidation and the penetration of free radicals into the cell (64).

In addition, changes in the plasma lipoprotein profile have been reported in diabetes mellitus, resulting in an increased risk of coronary heart disease (65). Additionally, all lipoproteins, including VLDL and LDL, undergo structural changes (6668). It should be emphasized that LDL modification may also be dependent on lipid peroxidation. In this case, it is noted that the lysine residues in the apolipoprotein B-100 (ApoB100) moiety are replaced by MDA (a product of the oxidation of polyunsaturated fatty acids) $(69,70)$. It should be mentioned that the observed decrease in MDA in the group of animals receiving naringenin could be related to the normalization of the lipid profile by reducing the LDL:HDL ratio presented in the previous article (33). It can be hypothesized that the tested natural compound reduces the concentration of lipid peroxides in the blood and lowers the level of ApoB100, which forms the LDL particle. In order to validate these assumptions, further research should be carried out on various stages of diabetes along with other markers, including the determination of the concentration of MDA-modified LDL and ApoB100 in the serum.
The concentration of AOPP in heart homogenates was higher in diabetic rats than in controls. Similar results were obtained by other researchers in the same tissue and model $(71,72)$. Lower AOPP concentrations were observed in rats treated with naringenin than in untreated animals. AOPP level in cardiac tissue of diabetic rats was also reduced in other experiments which confirms the results obtained in the presented study. It was proven that AOPP levels in cardiac tissue may be reduced by the administration of Hibiscus sabdariffa extract or naringenin glycoside - naringin $(71,72)$. The obtained values are the most appropriate and consistent with the available research results because AOPP is created due to the disturbance of the oxidation-reduction balance, glycoxidation processes, and accompanying inflammatory processes (71-73).

An insignificant decreased level of vitamin C was observed in the hearts of diabetic rats. A similar result was obtained in previous experiments in rats with induced type 1 diabetes, in which hearts were used for analysis $(38,57)$. It should be noted that measurements were also made in homogenates of other organs, such as the liver, pancreas, kidneys, and eye lenses. Vitamin $\mathrm{C}$ levels were also decreased in these organs compared to non-diabetic animals. $(44,74)$.

Low levels of vitamin $\mathrm{C}$ in the tissue are likely due to the neutralization of oxygen free radicals resulting from an imbalance in oxidation and reduction processes. It was found that the administration of naringenin insignificant increased the concentration of vitamin $\mathrm{C}$ in the myocardium in diabetic rats. Moreover, the observed lack of statistical significance does not exclude biological or clinical influence. The observations made are analogous to the data found in other experiments on the development of diabetes complications in the heart (38, $57)$ and other organs $(44,74)$.

Induction of type 1 diabetes mellitus increased TOS (statistical tendency) and OSI in the absence of TAR changes in the DM rats. This suggests increased oxidative stress in diabetic rats compared to healthy animals. Despite the lack of significant changes in TOS and TAR. The same conclusions were made by other experimenters in different models and organs (75-77), as well as in clinical trials in diabetic nephropathy patients suffering from insulin-dependent diabetes (78). In rats receiving naringenin, an increase in TAR (statistical tendency) and a decrease in OSI were noted, as well as no significant differences in TOS in relation to DM animals. This confirms the antioxidant effect of naringenin in the analyzed tissue. This 
observation indirectly points to the important role of free radical processes in the pathogenesis of the development of multiorgan complications related to insulin-dependent and non-insulin-dependent diabetes $(76,79)$.

The mechanism of the cardioprotective action of naringenin in type 1 diabetes mellitus has been initially elucidated. The team of researchers led by Zhang said the above flavanone probably inhibited myocardial hypertrophy by increasing the expression of cytochrome P450 (family 2, subfamily j, polypeptide 3 ), peroxisome proliferator-activated receptors (PPAR), and an increase in epoxyeicosatrienoic acids $(14,15$-EET) $(80,81)$. Moreover, naringenin prevents ischemia-reperfusion damage to the myocardium after acute myocardial infarction in diabetic rats. There was an increase in activation of the PI3K/AKT signaling pathway, which indirectly regulates cardiac contraction and the function of calcium channels. Additionally, increased gene expression for microRNA-126 has been shown to act angiogenic in heart tissue (14).

\section{CONCLUSIONS}

Based on the conducted research, it can be concluded that naringenin negatively affects the development of oxidative stress in the cardiac tissue of rats with streptozotocin-induced type 1 diabetes. In the present experiment, selected biochemical parameters were determined in homogenates of the heart of Wistar males diabetic rats. In the future, histological diagnostics should be performed, consisting of histopathology and immunohistochemistry combined with computer image analysis. Moreover, the profile of proinflammatory cytokines in diabetic animals and animals treated with test compounds must be assessed. Additionally, mark intracellular signaling pathways as well as markers of apoptosis and autophagy.

Therefore, multidirectional scientific experiments regarding naringenin should be continued in order to definitively clarify their role in the treatment of type 1 diabetes and its complications. These experiments would help to understand if these plant-derived compounds may have therapeutic potential in preventing the development of pathological changes that eventually lead to diabetic cardiomyopathy.

\section{Acknowledgments}

This study was supported by the Medical University of Silesia (grant No. PCN-2-069/N/0/O).

\section{Conflict of interest}

The authors report that there are no conflicts of interest.

\section{LITERATURE}

1. American Diabetes Association.: Diabetes Care 41(Suppl 1), 13 (2018).

2. Ogurtsova K., da Rocha Fernandes J.D., Huang Y., Linnenkamp U., Guariguata L., et al.: Diabetes Res. Clin. Pract. 128, 40 (2017).

3. Atkinson M.A., Eisenbarth G.S., Michels A.W.: Lancet 383, 69 (2014).

4. Maritim A.C., Sanders R.A., Watkins J.B.: J. Biochem. Mol. Toxicol. 17, 24 (2003).

5. Filardi T., Ghinassi B., Di Baldassarre A., Tanzilli G., Morano S., et al.: Int. J. Mol. Sci. 20, 66 pages (2019).

6. Alonso N., Moliner P., Mauricio D.: Adv. Exp. Med. Biol. 1067, 197 (2018).

7. Dhalla N.S., Shah A.K., Tappia P.S.: Int. J. Mol. Sci. 21, 37 pages (2020).

8. Tan Y., Zhang Z., Zheng Ch., Wintergerst K.A., Keller B.B., et al.: Nat. Rev. Cardiol. 17, 585 (2020).

9. Guido M.C., Marques A.F., Tavares E.R., Tavares de Melo M.D., Salemi V.M.C., et al.: Oxid. Med. Cell Longev. 2017, 29 pages (2017).

10. Saisho Y.: Int. J. Mol. Sci. 15, 590 (2014).

11. Khunti K., Davies M., Majeed A., Thorsted B.L., Wolden M.L., et al.: Diabetes Care 38, 316 (2015).

12. Zaidun N.H., Thent Z.Ch., Latiff A.A.: Life Sci. 208, 111 (2018).

13. Mahmoud A.M., Bautista R.J.H., Sandhu M.A., Hussein O.E.: Oxid. Med. Cell Longev. 2019, 85 pages (2019).

14. Li S.H., Wang M.S., Ke W.L., Wang M.R.: Exp. Ther. Med. 810, 11 pages (2021).

15. Furman B.L.: Curr. Protoc. Pharmacol. 70, 5 (2015).

16. Goyal S.N., Reddy N.M., Patil K.R., Nakhate K.T., Ojha S., et al.: Chem. Biol. Interact. 244, 49 (2016).

17. Qinna N.A., Badwan A.A.: Drug Des. Devel. Ther. 9, 2515 (2015).

18. Lowry O.H., Rosebrough N.J., Farr A.L., Randall R.J.: J. Biol. Chem. 193, 265 (1951).

19. Jagota S.K., Dani H.M.: Anal. Biochem. 127, 178 (1982).

20. Witko-Sarsat V., Friedlander M., CapeillèreBlandin C., Nguyen-Khoa T., Nguyen A.T., et al.: Kidney Int. 49, 1304 (1996). 
21. Buege J.A., Aust S.D.: Methods Enzymol. 52, 302 (1978).

22. Erel O.: Clin. Biochem. 38, 1103 (2005).

23. Erel O.: Clin. Biochem. 37, 112 (2004).

24. Sai Varsha M.K.N., Thiagarajan R., Manikandan R., Dhanasekaran G.: Nutrition 31, 214 (2015).

25. Talebi A.R., Mangoli E., Nahangi H., Anvari M., Pourentezari M., et al.: Eur. J. Obstet. Gynecol. Reprod. Biol. 181, 32 (2014).

26. Mutavdzin S., Gopcevic K., tankovic S.: Oxid. Med. Cell. Longe. 2019, 50 pages (2019).

27. Zych M., Wojnar W., Borymski S.: Antioxidants 8, 579 (2019).

28. Li Ch.L., Liu B., Wang Z.Y., Xie F., Wen Q., et al.: J. Mol. Cell. Cardiol. 139, 98 (2020).

29. Sun Y., Zhou S., Guo H., Zhang J., Ma T., et al.: Metabolism 102, 13 pages (2020).

30. Ali T.M., Abo-Salem O.M., El Esawy B.H., El Askary A.: Am. J. Med. Sci. 359, 32 (2020).

31. Das A.K., Chandrasekar S., Laxmanan A., Balasubramanyam A., Ramakrishnan S.: Indian J. Exp. Biol. 24, 592 (1986).

32. Lawrance Christopher C., Mathuram L.N., Genitta G., Cyrus I., Jaya Sundar S.: Int. J. Cardiol. 88, 183 (2003).

33. Wojnar W., Zych M., Kaczmarczyk-Sedlak I.: Biomed. Pharmacother. 108, 974 (2018).

34. Hu J., Klein J.D., Du J., Wang X.H.: Endocrinology 149, 5384 (2008).

35. Sharma I., Aaradhya M., Kodikonda M., Naik PR.: Springerplus 4, 212 (2015).

36. Rani N., Bharti S., Bhatia J., Nag T.C., Ray R. et al.: Chem. Biol. Interact. 250, 59 (2016).

37. Muruganandan S., Gupta S., Kataria M., Lal J., Gupta P.K.: Toxicology 176, 165 (2002).

38. Al-Numair K.S., Chandramohan G., Veeramani Ch., Alsaif M.A.: Redox Rep. 20, 198 (2015).

39. Agrawal O.Y., Sharma P.K., Shrivastava B.: PLoS One 9, el11212 (2014).

40. Othman A.I., El-Sawi M.R., El-Missiry M.A., Abukhalil M.H.: Biomed. Pharmacother. 94, 362 (2017).

41. Aju B.Y., Rajalakshmi R., Mini S.: Heliyon 6, 26 pages (2020).

42. Bhatti R., Sharma S., Singh J., Ishar M.P.S.: Pharm. Biol. 49, 1137 (2011).

43. Govindaraj J., Pillai S.S.: Mol. Cell. Biochem. 404, 143 (2015).

44. Kanchana G., Shyni W.J., Rajadurai M., Periasamy R.: Glob. J. Pharmacol. 5, 33 (2011).

45. Shahmohamady P., Eidi A., Mortazavi P., Panahi N., Minai-Tehrani D.: Pol. J. Pathol. 69, 266 (2018).
46. Patel H., Chen J., Das K.C., Kavdia M.: Cardiovasc. Diabetol. 12, 1 (2013).

47. Zhang Y.F., Meng N.N., Li H.Z., Wen Y.J., Liu J.T. et al:: China Journal of Chinese Materia Medica 43, 596 (2018).

48. Zhang N., Yang Z., Xiang S.Z., Jin Y.G., Wei W.Y., et al.: Mol. Cell Biochem. 417, 87 (2016).

49. Bao H., Chen L.: Zhongguo Zhong Yao Za Zhi 36, 1503 (2011).

50. You Q., Wu Z., Wu B., Liu Ch., Huang R. et al.: J. Endocrinol. 230, 197 (2016).

51. Kapoor R., Kakkar P.: Toxicol. Rep. 1, 569 (2014).

52. Finkel T., Holbrook N.J.: Nature 408, 239 (2000).

53. Finkel T.: Curr. Opin. Cell Biol. 15, 247 (2003).

54. Meister A., Anderson M.E.: Annu. Rev. Biochem. 52, 711 (1983).

55. Vassort G., Turan B.: Cardiovasc. Toxicol. 10, 73 (2010).

56. Kalinina E.V., Chernov N.N., Novichkova M.D.: Biochemistry 79, 1562 (2014).

57. Saddala R.R., Thopireddy L., Ganapathi N., Kesireddy S.R.: Exp. Toxicol. Pathol. 65, 15 (2013).

58. Shrilatha B., Muralidhara N.: Reprod. Toxicol. 23, 578 (2007).

59. Raza H., John A., Howarth F.C.: Int. J. Mol. Sci. 13, 16241 (2012).

60. Çelık V.K., Şahın Z.D., Sari I., Bakir S.: Exp. Diabetes Res. 2012: 386831 (2012).

61. Soetikno V., Sari F.R., Sukumaran V., Lakshmanan A.P., Mito S., et al.: Eur. J. Pharm. Sci. 47, 604 (2012).

62. Roslan J., Giribabu N., Karim K., Salleh N.: Biomed. Pharmacother. 86, 570 (2017).

63. Wang G., Li W., Lu X., Bao P., Zhao X.: J. Diabetes Complications 26, 259 (2012).

64. Hernández-Aquino E., Muriel P.: World J. Gastroenterol. 24, 1679 (2018).

65. Betteridge J.: Lipid disorders in diabetes mellitus, Blackwell Science Publishers, London 1997.

66. Bar-on H., Levy E., Oschry Y., Ziv E., Shafrir E.: Biochim. Biophys. Acta. 27, 115 (1984).

67. O'Looney P., Irwin D., Briscoe P., Vahouny GV.: J. Biol. Chem. 10, 428 (1985).

68. Böttiger LE.: J. Intern. Med. Suppl. 736, 69 (1994).

69. Holvoet P.: Ther. Apher. 3, 287 (1999).

70. Yamada T., Ogawa K., Tanaka T.D., Nagoshi T., Minai K., et al.: Diabetes Res. Clin. Pract. 161, 108036 (2020). 
71. Yusof N.L.M., Zainalabidin S., Fauzi N.M., Budin S.B.: Appl. Physiol. Nutr. Metab. 43, 1224 (2018).

72. Adebiyi O.A., Adebiyi O.O., Owira P.M.: PLoS One 11, e0149890 (2016).

73. Piwowar A.: Polski Merkuriusz Lekarski: organ Polskiego Towarzystwa Lekarskiego 28, 227 (2010) (in Polish).

74. Wojnar W., Kaczmarczyk-Sedlak I., Zych M.: Pharmacol. Rep. 69, 995 (2017).

75. Turhan U., Yilmaz E., Gul M., Melekoglu R., Turkoz Y,. et al.: Acta Cir. Bras. 33(4), 306 (2018).
76. Heidarisasan S., Ziamajidi N., Karimi J., Abbasalipourkabir R.: Iran J. Basic Med. Sci. 21, 1035 (2018).

77. Hazman Ö., Ovalı S.: Inflammation 38, 1012 (2015).

78. Aslan M., Sabuncu T., Kocyigit A., Celik H., Selek S.: Nutr. Metab. Cardiovasc. Dis. 17, 734 (2007).

79. Rahimi R., Karimi J., Khodadadi I.: Biomed. Pharmacother. 101, 244 (2018).

80. Zhang J., Qiu H., Huang J., Ding S., Huang B., et al.: Biomed. Pharmacother. 109, 1498 (2019).

81. Zhang J., Qiu H., Huang J., Ding S., Huang B., et al.: Biochem. Biophys. Res. Commun. 502, 55 (2018). 